\title{
A Time Delay Predator-Prey System with Three-Stage-Structure
}

\author{
Qiaoqin Gao' and Zhen Jin ${ }^{2}$ \\ ${ }^{1}$ Department of Mathematics, Lvliang University, Lishi, Lvliang City, Shanxi 033001, China \\ ${ }^{2}$ Department of Mathematics, Shanxi University, Taiyuan, Shanxi 030006, China
}

Correspondence should be addressed to Qiaoqin Gao; gaoqqltj@163.com

Received 26 December 2013; Accepted 11 March 2014; Published 27 March 2014

Academic Editors: J. Fernández and D. Xu

Copyright (C) 2014 Q. Gao and Z. Jin. This is an open access article distributed under the Creative Commons Attribution License, which permits unrestricted use, distribution, and reproduction in any medium, provided the original work is properly cited.

\begin{abstract}
A predator-prey system was studied that has a discrete delay, stage-structure, and Beddington-DeAngelis functional response, where predator species has three stages, immature, mature, and old age stages. By using of Mawhin's continuous theorem of coincidence degree theory, a sufficient condition is obtained for the existence of a positive periodic solution.
\end{abstract}

\section{Introduction}

The dynamic relationship between the predator and the prey has long been and will continue to be one of the dominant themes in both ecology and mathematical ecology due to its universal existence and importance. The traditional predatorprey model has been studied extensively (see [1-3] and references cited therein). Since the pioneering and original work of Aiello and Freedman (see [4]) considered the difference between immature population and mature population, stagestructured models have attracted great attention and have been extensively researched in recent years (see, e.g., [5-9] and the references cited therein). They studied the stagestructured model with time delay, cannibalism, impulsive harvesting strategies and response functions, and many interesting results concerning stability of equilibrium state and existence of periodic solutions. At present, many authors considered species model with two stage-structures, but in real life many mammals (such as humans) growth is divided into three stages: childhood, adulthood, and old age; and almost all the insect growths are divided into eggs, larvae, and adults of three stages. Therefore, the three-stage- structure predatorprey model is studied that is more close to the reality. Recently, more and more papers, but still not too much, considered models with three-stage-structure such as [10-12].

Arditi and Ginzburg [13] first put forward the following ratio-dependent predator-prey system:

$$
\dot{x}=x(a-b x)-\frac{c x y}{m y+x},
$$

$$
\dot{y}=y\left(-d+\frac{f x}{m y+x}\right) .
$$

Later, Fan and Kuang [14] have explored the dynamics of the nonautonomous, spatially homogeneous, and continuous time predator-prey system with the Beddington-DeAngelis functional response in a more general form:

$$
\begin{gathered}
\dot{x}=x(a(t)-b(t) x)-\frac{c(t) x y}{\alpha(t)+\beta(t) x+\gamma(t) y}, \\
\dot{y}=y\left(-d(t)+\frac{f(t) x y}{\alpha(t)+\beta(t) x+\gamma(t) y}\right) .
\end{gathered}
$$

Recently, Chen et al. [8] studied a delayed predator-prey system with Holling II type response and stage-structure for predator of the form

$$
\begin{gathered}
\dot{x}(t)=x(t)\left(r(t)-a(t) x\left(t-\tau_{1}(t)\right)\right)-\frac{b(t) x(t) y_{2}(t)}{1+m x(t)}, \\
\dot{y}_{1}(t)=\frac{c(t) x\left(t-\tau_{2}(t)\right) y_{2}\left(t-\tau_{2}(t)\right)}{1+m x\left(t-\tau_{2}(t)\right)} \\
-\left(D(t)+v_{1}(t)\right) y_{1}(t), \\
\dot{y}_{2}(t)=D(t) y_{1}(t)-v_{2}(t) y_{2}(t) .
\end{gathered}
$$


In the present paper, motivated by the above work, we investigate a time delay predator-prey system with threestage-structure for predator and Beddington-DeAngelis functional response of the form

$$
\begin{aligned}
\dot{x}_{1}(t)= & \frac{d(t) y\left(t-\tau_{2}(t)\right) x_{2}\left(t-\tau_{2}(t)\right)}{\alpha(t)+\beta(t) y\left(t-\tau_{2}(t)\right)+\gamma(t) x_{2}\left(t-\tau_{2}(t)\right)} \\
& -\left(d_{1}(t)+r_{1}(t)\right) x_{1}(t), \\
\dot{x}_{2}(t)= & r_{1}(t) x_{1}(t)-d_{2}(t) x_{2}(t) \\
& -r_{2}(t) x_{2}(t)-e_{2}(t) x_{2}^{2}(t), \\
\dot{x}_{3}(t)= & r_{2}(t) x_{2}(t)-d_{3}(t) x_{3}(t), \\
\dot{y}(t)= & y(t)\left(b(t)-a(t) x\left(t-\tau_{1}(t)\right)\right. \\
& \left.-\frac{c(t) x_{2}(t)}{\alpha(t)+\beta(t) y(t)+\gamma(t) x_{2}(t)}\right),
\end{aligned}
$$

with initial conditions

$$
\begin{aligned}
& x_{i}(\theta)=\varphi_{i}(\theta)>0 \quad(i=1,2,3), \\
& y(\theta)=\varphi_{4}(\theta)>0, \quad \text { for } \theta \in[-\tau, 0], \\
& x_{i}(0)>0, \quad i=1,2,3, \quad y(0)>0,
\end{aligned}
$$

where $x_{1}(t), x_{2}(t)$, and $x_{3}(t)$ are the densities of immature, mature, and the old age predator at time $t$, respectively; $y(t)$ represents the density of prey at time $t . \tau=\max _{t \in[0, \omega]}\left\{\tau_{1}(t)\right.$, $\left.\tau_{2}(t)\right\}, \tau_{1}(t) \geq 0$ is delay due to prey densities and $\tau_{2}(t) \geq 0$ is delay due to gestation of predator. The death rates of the immature, mature, and old age predator are proportional to the fact that existing immature, mature, and old age predator population with respective proportionality $d_{1}(t), d_{2}(t)$, $d_{3}(t), r_{1}(t)$ denote the rate of transformation from immature predator into mature predator; $r_{2}(t)$ is the rate of transformation from mature predator into old age predator; $k(t)=$ $(d(t) / c(t))(0<k(t) \leq 1)$ is the transformation coefficient from prey into the immature predators. Let $d_{1}(t)+r_{1}(t)=$ $m(t)$ and $d_{2}(t)+r_{2}(t)=n(t)$.

In this paper, we always make the following assumption for the system (4).

(H1) The coefficients $a(t), b(t), c(t), d(t), d_{i}(t)(i=1,2,3)$, $\alpha(t), \beta(t), \gamma(t), e_{2}(t)$ and $r_{i}(t)(i=1,2)$ are all positive $\omega$-periodic continuous function in $R=[0, \infty)$.

The organization of this paper is as follows. In the next section, we give two lemmas for preparing the study of the existence of positive periodic solutions. In Section 3, by using Gains and Mawhin's continuation theorem of coincidence degree theory, a sufficient condition on the existence of positive periodic solutions for the model is obtained.

\section{Preliminaries}

For ecological reasons, we consider the initial function of the system (4) only in $R_{+}^{4} \times R_{+}^{1}=\left\{\left(x_{1}(t), x_{2}(t), x_{3}(t), y(t)\right)^{T}: x_{i} \geq\right.$ $0, y \geq 0, i=1,2,3\} \times[-\tau, 0]$.
Supposing that $f(t), t \in[0, \infty)$ is a continuous function with periodic $\omega$, we denote

$$
\begin{aligned}
f^{L} & =\min _{t \in[0, \omega]}\{f(t)\}, \\
f^{M} & =\max _{t \in[0, \omega]}\{f(t)\}, \quad \bar{f}=\frac{1}{\omega} \int_{0}^{\omega} f(t) d t .
\end{aligned}
$$

Using the above definitions, the coefficients of the system (4) not only are all positive and periodic function with common periodic solution but also satisfy the following two items and hold true:

$$
\begin{aligned}
& \min _{i=1,2,3}\left\{a^{L}, b^{L}, c^{L}, d^{L}, m^{L}, n^{L}, d_{i}^{L}, r_{i}^{L}, e_{2}^{L}, \alpha^{L}, \beta^{L}, \gamma^{L}\right\}>0 \\
& \max _{i=1,2,3}\left\{a^{M}, b^{M}, c^{M}, d^{M}, m^{M}, n^{M}, d_{i}^{M}, r_{i}^{M}, e_{2}^{M}, \alpha^{M}, \beta^{M}, \gamma^{M}\right\} \\
& <+\infty
\end{aligned}
$$

In order to obtain the existence of at least one periodic solution of the system (4), the method used the applications of the continuation theorem of coincidence degree. For convenience, we introduce a few concepts and results about the coincidence degree as follows.

Let $X, Y$ be real Banach spaces, let $L:$ Dom $L \subset X \rightarrow Z$ be a linear mapping, and let $N: X \rightarrow Y$ be a continuous mapping. The mapping $L$ will be called a Fredholm mapping of index zero if $\operatorname{dim} \operatorname{Ker} L=\operatorname{codim} \operatorname{Im} L<\infty$ and $\operatorname{Im} L$ is closed in $Y$. If $L$ a is Fredholm mapping of index zero, then there exist continuous projectors $P: X \rightarrow X$ and $Q: Z \rightarrow$ $Z$ such that $\operatorname{Im} P=\operatorname{Ker} L$ and $\operatorname{Ker} Q=\operatorname{Im} L=\operatorname{Im}(I-Q)$. It follows that the restriction $\left.L\right|_{\text {Dom } L \cap K e r P}:(I-P) X \rightarrow \operatorname{Im} L$ is invertible. Denote the inverse of $\left.L\right|_{\operatorname{Dom} L \cap \operatorname{Ker} P}$ by $K_{P}$.

Let $\Omega$ be an open bounded subset of $X$ and denote the closure of $\Omega$ by $\bar{\Omega}$. A mapping $N$ is said to be $L$-compact on $\bar{\Omega}$. If $Q N(\bar{\Omega})$ is bounded and $K_{P}(I-Q) N: \bar{\Omega} \rightarrow X$ is compact, since $\operatorname{Im} Q$ is isomorphic to $\operatorname{Ker} L$, then there exists an isomorphism $J: \operatorname{Im} Q \rightarrow \operatorname{Ker} L$.

Lemma 1 (Mawhin's continuation theorem [15, page 40]). Let $X, Y$ be two Banach spaces, let $L$ be a Fredholm mapping of index zero and let $N: \bar{\Omega} \rightarrow Y$ be a continuous operator which is L-compact on $\bar{\Omega}$. Assume that,

(a) for each $\lambda \in(0,1), x \in \partial \Omega \cap \operatorname{Dom} L, L x \neq \lambda N x$;

(b) for each $x \in \partial \Omega \cap \operatorname{Ker} L, Q N x \neq 0$;

(c) $\operatorname{deg}(J Q N, \Omega \cap \operatorname{Ker} L, 0) \neq 0$.

Then the operator equation $L x=N x$ has at least one solution in $\bar{\Omega} \cap \operatorname{Dom} L$.

Lemma 2. int $R_{+}^{4}$ is a positively invariant region of the system (4).

\section{Existence of Periodic Solution}

Theorem 3. Assume that the system (4) satisfies (H1) and the following: 
(H2) $r_{1}^{M} d^{M}>n^{L} m^{L} \beta^{L}$;

(H3) $\bar{b}>\overline{(c / r)}$;

(H4) $r_{1}^{L} d^{L} A_{4}>m^{M} n^{M}\left(\alpha^{M}+\beta^{M} A_{4}\right)$.

Then the system (4) with initial condition (5) has at least one $\omega$-periodic solution.

Proof. Let

$$
x_{i}(t)=e^{u_{i}(t)} \quad(i=1,2,3), \quad y(t)=e^{u_{4}(t)} .
$$

Then the system (4) transforms correspondingly to the following equations:

$$
\begin{aligned}
\dot{u}_{1}(t)= & \frac{d(t) e^{u_{4}\left(t-\tau_{2}(t)\right)} e^{u_{2}\left(t-\tau_{2}(t)\right)-u_{1}(t)}}{\alpha(t)+\beta(t) e^{u_{4}\left(t-\tau_{2}(t)\right)}+\gamma(t) e^{u_{2}\left(t-\tau_{2}(t)\right)}}-m(t), \\
\dot{u}_{2}(t)= & r_{1}(t) e^{u_{1}(t)-u_{2}(t)}-n(t)-e_{2}(t) e^{u_{2}(t)} \\
\dot{u}_{3}(t)= & r_{2}(t) e^{u_{2}(t)-u_{3}(t)}-d_{3}(t) \\
\dot{u}_{4}(t)= & b(t)-a(t) e^{u_{4}\left(t-\tau_{1}(t)\right)} \\
& -\frac{c(t) e^{u_{2}(t)}}{\alpha(t)+\beta(t) e^{u_{4}(t)}+\gamma(t) e^{u_{2}(t)}} .
\end{aligned}
$$

It is easy to see that if the system (9) has a $\omega$-periodic solution $u^{*}(t)=\left(u_{1}^{*}, u_{2}^{*}, u_{3}^{*}, u_{4}^{*}\right)^{T}$, then the system (4) has correspondingly a positive $\omega$-periodic solution $\left(x_{1}^{*}, x_{2}^{*}, x_{3}^{*}, y^{*}\right)^{T}=\left(e^{u_{1}^{*}}\right.$, $\left.e^{u_{2}^{*}}, e^{u_{3}^{*}}, e^{u_{4}^{*}}\right)^{T}$. Thus, to complete the proof, suffice it to say that the system (9) has at least one positive $\omega$-periodic solution.

Define $X=Y=\left\{u(t)=\left(u_{1}(t), u_{2}(t), u_{3}(t), u_{4}(t)\right)^{T} \epsilon\right.$ $\left.C\left(R, R^{4}\right), u(t+\omega)=u(t)\right\}$, and $\|u\|=\sum_{i=1}^{4} \max _{t \in[0, \omega]}\left|u_{i}(t)\right| ;$ then $X$ and $Y$ are Banach spaces with the norm $\|\cdot\|$.

Let $N u=\left(N_{1}(t), N_{2}(t), N_{3}(t), N_{4}(t)\right)^{T}, u \in X, L u=$ $\dot{u}(t)=d u(t) / d t, P u=(1 / \omega) \int_{0}^{\omega} u(t) d t, u \in X$, and $Q y=$ $(1 / \omega) \int_{0}^{\omega} y(t) d t, y \in Y$, where

$$
\begin{gathered}
N_{1}(t)=\frac{d(t) e^{u_{4}\left(t-\tau_{2}(t)\right)} e^{u_{2}\left(t-\tau_{2}(t)\right)-u_{1}(t)}}{\alpha(t)+\beta(t) e^{u_{4}\left(t-\tau_{2}(t)\right)}+\gamma(t) e^{u_{2}\left(t-\tau_{2}(t)\right)}}-m(t), \\
N_{2}(t)=r_{1}(t) e^{u_{1}(t)-u_{2}(t)}-n(t)-e_{2}(t) e^{u_{2}(t)}, \\
N_{3}(t)=r_{2}(t) e^{u_{2}(t)-u_{3}(t)}-d_{3}(t), \\
N_{4}(t)=b(t)-a(t) e^{u_{4}\left(t-\tau_{1}(t)\right)} \\
-\frac{c(t) e^{u_{2}(t)}}{\alpha(t)+\beta(t) e^{u_{4}(t)}+\gamma(t) e^{u_{2}(t)}} .
\end{gathered}
$$

Thus, the system (9) can be written in the form $L u=N u, u \in$ $X$.

Obviously, $\operatorname{Ker} L=R^{4}, \operatorname{Im} L=\left\{u(t) \in Z, \int_{0}^{\omega} u(t) d t=0\right\}$ is closed in $Y$ and $\operatorname{dim} \operatorname{Ker} L=4=\operatorname{Codim} \operatorname{Im} L$ and $P, Q$ are continuous projectors such that $\operatorname{Im} P=\operatorname{Ker} L, \operatorname{Ker} Q=$
$\operatorname{Im} L=\operatorname{Im}(I-Q)$. Therefore, $L$ is a Fredholm mapping of index zero. Furthermore, the inverse $K_{P}: \operatorname{Im} L \rightarrow \operatorname{Ket} P \cap$ Dom $L$ exists and has the form

$$
K_{P}(u)=\int_{0}^{t} u(s) d s-\frac{1}{\omega} \int_{0}^{\omega} \int_{0}^{t} u(s) d s d t .
$$

Thus

$$
\begin{gathered}
Q N u=\frac{1}{\omega} \int_{0}^{\omega} N(t) d t \\
K_{P}(I-Q) N u=\int_{0}^{t} N(s) d s-\frac{1}{\omega} \int_{0}^{\omega} \int_{0}^{t} N u(s) d s d t \\
-\left(\frac{t}{\omega}-\frac{1}{2}\right) \int_{0}^{\omega} N u(s) d s .
\end{gathered}
$$

Obviously, $Q N$ and $K_{P}(I-Q) N$ are continuous by the Lebesgue theorem; it is not difficult to show that $Q N(\bar{\Omega})$ is bounded and $\overline{K_{P}(I-Q) N(\bar{\Omega})}$ is compact for any open bounded set $\Omega \subset X$ by the Arzela-Ascoli theorem. Hence $N$ is $L$-compact on $\bar{\Omega}$ for any open bounded set $\Omega \subset X$.

In order to apply Lemma 1, we need to search for an appropriate open and bounded subset $\Omega \subset X$. Corresponding to the operator equation, $L u=\lambda N u, \lambda \in(0,1)$, we have

$$
\begin{gathered}
\dot{u}_{1}(t)=\lambda\left(\frac{d(t) e^{u_{4}\left(t-\tau_{2}(t)\right)} e^{u_{2}\left(t-\tau_{2}(t)\right)-u_{1}(t)}}{\alpha(t)+\beta(t) e^{u_{4}\left(t-\tau_{2}(t)\right)}+\gamma(t) e^{u_{2}\left(t-\tau_{2}(t)\right)}}-m(t)\right), \\
\dot{u}_{2}(t)=\lambda\left(r_{1}(t) e^{u_{1}(t)-u_{2}(t)}-n(t)-e_{2}(t) e^{u_{2}(t)}\right), \\
\dot{u}_{3}(t)=\lambda\left(r_{2}(t) e^{u_{2}(t)-u_{3}(t)}-d_{3}(t)\right), \\
\dot{u}_{4}(t)=\lambda\left(b(t)-a(t) e^{u_{4}\left(t-\tau_{1}(t)\right)}\right. \\
\left.-\frac{c(t) e^{u_{2}(t)}}{\alpha(t)+\beta(t) e^{u_{4}(t)}+\gamma(t) e^{u_{2}(t)}}\right) .
\end{gathered}
$$

Suppose that $u=u(t) \in X$ is a solution to (13) for a certain $\lambda \in(0,1)$. Integrating (13) over the interval $[0, \omega]$ leads to

$$
\begin{gathered}
\int_{0}^{\omega} \frac{d(t) e^{u_{4}\left(t-\tau_{2}(t)\right)} e^{u_{2}\left(t-\tau_{2}(t)\right)-u_{1}(t)}}{\alpha(t)+\beta(t) e^{u_{4}\left(t-\tau_{2}(t)\right)}+\gamma(t) e^{u_{2}\left(t-\tau_{2}(t)\right)}} d t=\bar{m} \omega, \\
\int_{0}^{\omega} r_{1}(t) e^{u_{1}(t)-u_{2}(t)} d t=\bar{n} \omega+\int_{0}^{\omega} e_{2}(t) e^{u_{2}(t)} d t, \\
\int_{0}^{\omega} r_{2}(t) e^{u_{2}(t)-u_{3}(t)} d t=\bar{d}_{3} \omega,
\end{gathered}
$$

$\int_{0}^{\omega}\left[a(t) e^{u_{4}\left(t-\tau_{1}(t)\right)}+\frac{c(t) e^{u_{2}(t)}}{\alpha(t)+\beta(t) e^{u_{4}(t)}+\gamma(t) e^{u_{2}(t)}}\right] d t$

$$
=\bar{b} \omega \text {. }
$$


It follows from (14) to (17) that

$$
\begin{aligned}
& \int_{0}^{\omega}\left|\dot{u}_{1}(t)\right| d t \\
& =\lambda \int_{0}^{\omega} \mid \frac{d(t) e^{u_{4}\left(t-\tau_{2}(t)\right)} e^{u_{2}\left(t-\tau_{2}(t)\right)-u_{1}(t)}}{\alpha(t)+\beta(t) e^{u_{4}\left(t-\tau_{2}(t)\right)}+\gamma(t) e^{u_{2}\left(t-\tau_{2}(t)\right)}} \\
& -m(t) \mid d t \leq 2 \bar{m} \omega=: l_{1}, \\
& \int_{0}^{\omega}\left|\dot{u}_{2}(t)\right| d t \\
& =\lambda \int_{0}^{\omega}\left|r_{1}(t) e^{u_{1}(t)-u_{2}(t)}-n(t)-e_{2}(t) e^{u_{2}(t)}\right| d t \\
& \leq 2 \bar{n} \omega+2 \int_{0}^{\omega} e_{2}(t) e^{u_{2}(t)} d t \\
& \int_{0}^{\omega}\left|\dot{u}_{3}(t)\right| d t \\
& =\lambda \int_{0}^{\omega}\left|r_{2}(t) e^{u_{2}(t)-u_{3}(t)}-d_{3}(t)\right| d t \\
& \leq 2 \bar{d}_{3} \omega=: l_{3} \text {, } \\
& \int_{0}^{\omega}\left|\dot{u}_{4}(t)\right| d t \\
& =\lambda \int_{0}^{\omega} \mid b(t)-a(t) e^{u_{4}\left(t-\tau_{1}(t)\right)} \\
& -\frac{c(t) e^{u_{2}(t)}}{\alpha(t)+\beta(t) e^{u_{4}(t)}+\gamma(t) e^{u_{2}(t)}} \mid d t \\
& \leq 2 \bar{b} \omega=: l_{4} \text {. }
\end{aligned}
$$

Multiplying the first equation of (13) by $e^{u_{1}(t)}$ and integrating it over $[0, \omega]$ lead to

$$
\begin{aligned}
& \int_{0}^{\omega} m(t) e^{u_{1}(t)} d t \\
& \quad=\int_{0}^{\omega} \frac{d(t) e^{u_{4}\left(t-\tau_{2}(t)\right)} e^{u_{2}\left(t-\tau_{2}(t)\right)}}{\alpha(t)+\beta(t) e^{u_{4}\left(t-\tau_{2}(t)\right)}+\gamma(t) e^{u_{2}\left(t-\tau_{2}(t)\right)}} d t
\end{aligned}
$$

which implies

$$
\begin{aligned}
m^{L} \int_{0}^{\omega} e^{u_{1}(t)} d t & \leq \int_{0}^{\omega} \frac{d(t)}{\beta(t)} e^{u_{2}\left(t-\tau_{2}(t)\right)} d t \\
& \leq \frac{d^{M}}{\beta^{L}} \int_{0}^{\omega} e^{u_{2}\left(t-\tau_{2}(t)\right)} d t \\
\int_{0}^{\omega} e^{u_{2}(t)} d t & =\int_{\tau_{2}(s)}^{\omega-\tau_{2}(s)} e^{u_{2}(t)} d t \\
& =\int_{0}^{\omega} e^{u_{2}\left(t-\tau_{2}(t)\right)} d t \geq \frac{m^{L} \beta^{L}}{d^{M}} \int_{0}^{\omega} e^{u_{1}(t)} d t
\end{aligned}
$$

Similarly, multiplying the second equation of (13) by $e^{u_{2}(t)}$ and integrating it over $[0, \omega]$ give

$$
\int_{0}^{\omega} e_{2}(t) e^{2 u_{2}(t)} d t+\int_{0}^{\omega} n(t) e^{u_{2}(t)} d t=\int_{0}^{\omega} r_{1}(t) e^{u_{1}(t)} d t
$$

which yields

$$
e_{2}^{L} \int_{0}^{\omega} e^{2 u_{2}(t)} d t+n^{L} \int_{0}^{\omega} e^{u_{2}(t)} d t \leq r_{1}^{M} \int_{0}^{\omega} e^{u_{1}(t)} d t .
$$

By using the inequalities $\left(\int_{0}^{\omega} e^{u_{2}(t)} d t\right)^{2} \leq \omega \int_{0}^{\omega} e^{2 u_{2}(t)} d t$ and from (23) and (25) as well as (H1), we have

$$
\begin{aligned}
\int_{0}^{\omega} e^{u_{2}(t)} d t & \geq \frac{m^{L} \beta^{L}}{d^{M}} \int_{0}^{\omega} e^{u_{1}(t)} d t \\
& \geq \frac{m^{L} \beta^{L}}{d^{M} r_{1}^{M}}\left(e_{2}^{L} \int_{0}^{\omega} e^{2 u_{2}(t)} d t+n^{L} \int_{0}^{\omega} e^{u_{2}(t)} d t\right) \\
& \geq \frac{m^{L} \beta^{L}}{d^{M} r_{1}^{M}}\left[\frac{e_{2}^{L}}{\omega}\left(\int_{0}^{\omega} e^{u_{2}(t)} d t\right)^{2}+n^{L} \int_{0}^{\omega} e^{u_{2}(t)} d t\right] .
\end{aligned}
$$

Hence

$$
\int_{0}^{\omega} e^{u_{2}(t)} d t \leq \omega \frac{d^{M} r_{1}^{M}-n^{L} m^{L} \beta^{L}}{m^{L} \beta^{L} e_{2}^{L}}=: \omega B_{2} .
$$

From (23) and (27), we have

$$
\int_{0}^{\omega} e^{u_{1}(t)} d t \leq \frac{d^{M}}{m^{L} \beta^{L}} \int_{0}^{\omega} e^{u_{2}(t)} d t \leq \omega \frac{B_{2} d^{M}}{m^{L} \beta^{L}}=: \omega B_{1} .
$$

Similarly, multiplying the third equation of (13) by $e^{u_{3}(t)}$ and integrating it over $[0, \omega]$ lead to

$$
\int_{0}^{\omega} d_{3}(t) e^{u_{3}(t)} d t=\int_{0}^{\omega} r_{2}(t) e^{u_{2}(t)} d t
$$

And, together with (27), we obtain

$$
\int_{0}^{\omega} e^{u_{3}(t)} d t \leq \frac{r_{2}^{M}}{d_{3}^{L}} \int_{0}^{\omega} e^{u_{2}(t)} d t \leq \omega \frac{B_{2} r_{2}^{M}}{d_{3}^{L}}=: \omega B_{3} .
$$

Integrating the fourth equation of $(13)$ over $[0, \omega]$ leads to

$$
\begin{aligned}
\int_{0}^{\omega} a(t) e^{u_{4}\left(t-\tau_{1}(t)\right)} d t \\
\quad=\int_{0}^{\omega} b(t) d t-\int_{0}^{\omega} \frac{c(t) e^{u_{2}(t)}}{\alpha(t)+\beta(t) e^{u_{4}(t)}+\gamma(t) e^{u_{2}(t)}} d t
\end{aligned}
$$

which implies

$$
\int_{0}^{\omega} e^{u_{4}(t)} d t \leq \omega \frac{b^{M}}{a^{L}}=: \omega B_{4} .
$$

Since $u(t) \in X$, there exist $\xi_{i}, \eta_{i} \in[0, \omega]$ such that

$$
u_{i}\left(\xi_{i}\right)=\max _{t \in[0, \omega]} u_{i}(t), \quad u_{i}\left(\eta_{i}\right)=\min _{t \in[0, \omega]} u_{i}(t), \quad i=1,2,3,
$$


in which, together with (27), (28), (30), and (32), we deduce

$$
u_{i}\left(\xi_{i}\right) \leq \ln B_{i}, \quad i=1,2,3,4
$$

In view of (19) and (27), we have

$$
\int_{0}^{\omega}\left|\dot{u}_{2}(t)\right| d t \leq 2 \bar{n} \omega+2 \omega e_{2}^{M} B_{2}=: l_{2} .
$$

Keeping in mind (18), (20), (21), and (34), we obtain that for $t \in[0, \omega]$

$$
u_{i}(t) \leq u_{i}\left(\xi_{i}\right)+\int_{0}^{\omega}\left|\dot{u}_{i}(t)\right| d t \leq \ln B_{i}+l_{i}, \quad i=1,2,3,4 .
$$

From (17), (33), and (H3), we have

$$
\begin{aligned}
a^{M} \omega e^{u_{4}\left(\eta_{4}\right)} \geq & a^{M} \int_{0}^{\omega} e^{u_{4}(t)} d t=a^{M} \int_{0}^{\omega} e^{u_{4}\left(t-\tau_{1}(t)\right)} d t \\
= & \int_{0}^{\omega} b(t) d t \\
& -\int_{0}^{\omega} \frac{c(t) e^{u_{2}(t)}}{\alpha(t)+\beta(t) e^{u_{4}(t)}+\gamma(t) e^{u_{2}(t)}} d t \\
\geq & \bar{b} \omega-\overline{\left(\frac{c}{\gamma}\right)} \omega .
\end{aligned}
$$

Set $A_{4}=(\bar{b}-\overline{(c / \gamma)}) / a^{M}$, and hence

$$
e^{u_{4}\left(\eta_{4}\right)} \geq A_{4}
$$

Equation (33) leads to

$$
\begin{gathered}
\frac{d\left(\eta_{1}\right) e^{u_{4}\left(\eta_{1}-\tau_{2}\left(\eta_{1}\right)\right)} e^{u_{2}\left(\eta_{1}-\tau_{2}\left(\eta_{1}\right)\right)-u_{1}\left(\eta_{1}\right)}}{\alpha\left(\eta_{1}\right)+\beta\left(\eta_{1}\right) e^{u_{4}\left(\eta_{1}-\tau_{2}\left(\eta_{1}\right)\right)}+\gamma\left(\eta_{1}\right) e^{u_{2}\left(\eta_{1}-\tau_{2}\left(\eta_{1}\right)\right)}} \\
-m\left(\eta_{1}\right)=0 \\
r_{1}\left(\eta_{2}\right) e^{u_{1}\left(\eta_{2}\right)-u_{2}\left(\eta_{2}\right)}-n\left(\eta_{2}\right)-e_{2}\left(\eta_{2}\right) e^{u_{2}\left(\eta_{2}\right)}=0, \\
\quad r_{2}\left(\eta_{3}\right) e^{u_{2}\left(\eta_{3}\right)-u_{3}\left(\eta_{3}\right)}-d_{3}\left(\eta_{3}\right)=0, \\
-\frac{c\left(\eta_{4}\right) e^{u_{4}\left(\eta_{4}-\tau_{1}\left(\eta_{4}\right)\right)}}{\alpha\left(\eta_{4}\right)+\beta\left(\eta_{4}\right) e^{u_{4}\left(\eta_{4}\right)}+\gamma\left(\eta_{4}\right) e^{u_{2}\left(\eta_{4}\right)}}=0 .
\end{gathered}
$$

Taking into account (38) and the monotonicity of $g(x)=$ $x /(x+l)$ leads to

$$
\begin{aligned}
& m^{M} e^{u_{1}\left(\eta_{1}\right)} \\
& \geq m\left(\eta_{1}\right) e^{u_{1}\left(\eta_{1}\right)} \\
& =\frac{d\left(\eta_{1}\right) e^{u_{4}\left(\eta_{1}-\tau_{2}\left(\eta_{1}\right)\right)} e^{u_{2}\left(\eta_{1}-\tau_{2}\left(\eta_{1}\right)\right)-u_{1}\left(\eta_{1}\right)}}{\alpha\left(\eta_{1}\right)+\beta\left(\eta_{1}\right) e^{u_{4}\left(\eta_{1}-\tau_{2}\left(\eta_{1}\right)\right)}+\gamma\left(\eta_{1}\right) e^{u_{2}\left(\eta_{1}-\tau_{2}\left(\eta_{1}\right)\right)}} \\
& \geq \frac{d^{L} A_{4} e^{u_{2}\left(\eta_{2}\right)}}{\alpha^{M}+\beta^{M} A_{4}+\gamma^{M} e^{u_{2}\left(\eta_{2}\right)}},
\end{aligned}
$$

$$
\begin{gathered}
e_{2}^{M} e^{2 u_{2}\left(\eta_{2}\right)}+n^{M} e^{u_{2}\left(\eta_{2}\right)} \\
\geq e_{2}\left(\eta_{2}\right) e^{2 u_{2}\left(\eta_{2}\right)}+n\left(\eta_{2}\right) e^{u_{2}\left(\eta_{2}\right)} \\
=r_{1}\left(\eta_{2}\right) e^{u_{1}\left(\eta_{2}\right)} \geq r_{1}^{L} e^{u_{1}\left(\eta_{1}\right)}, \\
d_{3}^{M} e^{u_{3}\left(\eta_{3}\right)} \geq d_{3}\left(\eta_{3}\right) e^{u_{3}\left(\eta_{3}\right)} \\
=r_{2}\left(\eta_{3}\right) e^{u_{2}\left(\eta_{3}\right)} \geq r_{2}^{L} e^{u_{2}\left(\eta_{2}\right)} .
\end{gathered}
$$

It follows from (40) and (41) that

$$
e_{2}^{M} e^{u_{2}\left(\eta_{2}\right)}+n^{M} \geq \frac{r_{1}^{L} d^{L} A_{4}}{m^{M}\left(\alpha^{M}+\beta^{M} A_{4}+\gamma^{M} e^{u_{2}\left(\eta_{2}\right)}\right)},
$$

which yields

$$
\begin{aligned}
e^{u_{2}\left(\eta_{2}\right)} \geq & \left(-\left(e_{2}^{M}\left(\alpha^{M}+\beta^{M} A_{4}\right)+n^{M} \gamma^{M}\right)\right. \\
& \left.+\sqrt{\left(e_{2}^{M}\left(\alpha^{M}+\beta^{M} A_{4}\right)+n^{M} \gamma^{M}\right)^{2}+4 A_{5}}\right) \\
& \times\left(2 e_{2}^{M} \gamma^{M}\right)^{-1}=: A_{2},
\end{aligned}
$$

where $A_{5}=e_{2}^{M} \gamma^{M}\left(\left(r_{1}^{L} d^{L} A_{4} / m^{M}\right)-n^{M}\left(\alpha^{M}+\beta^{M} A_{4}\right)\right)$. From (40), (42), and (44), we have

$$
\begin{gathered}
e^{u_{1}\left(\eta_{1}\right)} \geq \frac{d^{L} A_{4} A_{2}}{m^{M}\left(\alpha^{M}+\beta^{M} A_{4}+\gamma^{M} A_{2}\right)}=: A_{1}, \\
e^{u_{3}\left(\eta_{3}\right)} \geq \frac{r_{2}^{L} A_{2}}{d_{3}^{M}}=: A_{3},
\end{gathered}
$$

which, together with (38), gives

$$
u_{i}\left(\eta_{i}\right) \geq \ln A_{i}, \quad i=1,2,3,4 .
$$

Moreover, from (18) to (21) and (35), we obtain

$$
\begin{aligned}
u_{i}(t) & \geq u_{i}\left(\eta_{i}\right)-\int_{0}^{\omega}\left|\dot{u}_{i}(t)\right| d t \\
& \geq \ln A_{i}-l_{i}, \quad t \in[0, \omega], \quad i=1,2,3,4 .
\end{aligned}
$$


It follows from (36) and (47) that

$$
\begin{array}{r}
\max _{t \in[0, \omega]}\left|u_{i}(t)\right|<\max \left\{\left|\ln B_{i}+l_{i}\right|,\left|\ln A_{i}-l_{i}\right|\right\}=R_{i} \\
i=1,2,3,4 .
\end{array}
$$

Clearly, $R_{i}(i=1,2,3,4)$ is independent of $\lambda$. From condition of Theorem 3, it is easy to know that there exist points $\zeta_{i} \in$ $[0, \omega], i=1,2$, such that the algebraic equations,

$$
\begin{gathered}
\frac{\bar{d} e^{u_{4}} e^{u_{2}-u_{1}}}{\alpha\left(\zeta_{1}\right)+\beta\left(\zeta_{1}\right) e^{u_{4}}+\gamma\left(\zeta_{1}\right) e^{u_{2}}}-\bar{m}=0, \\
\overline{r_{1}} e^{u_{1}-u_{2}}-\bar{n}-\overline{e_{2}} e^{u_{2}}=0, \\
\overline{r_{2}} e^{u_{2}-u_{3}}-\overline{d_{3}}=0, \\
\bar{b}-\bar{a} e^{u_{4}}-\frac{\bar{c} e^{u_{2}}}{\alpha\left(\zeta_{2}\right)+\beta\left(\zeta_{2}\right) e^{u_{4}}+\gamma\left(\zeta_{2}\right) e^{u_{2}}}=0,
\end{gathered}
$$

have a unique solution $\left(v_{1}^{*}, v_{2}^{*}, v_{3}^{*}, v_{4}^{*}\right)^{T}$.

Set $H=\sum_{i=1}^{4} R_{i}+R_{0}$, where $R_{0}$ is taken sufficiently large such that the unique solution to (49) satisfies $\|\left(v_{1}^{*}, v_{2}^{*}\right.$, $\left.v_{3}^{*}, v_{4}^{*}\right)^{T} \|=\left|v_{1}^{*}\right|+\left|v_{2}^{*}\right|+\left|v_{3}^{*}\right|+\left|v_{4}^{*}\right|<R_{0}$.

We take $\Omega=\left\{u(t)=\left(u_{1}(t), u_{2}(t), u_{3}(t), u_{3}(t)\right)^{T} \in X\right.$ : $\|u\|<M\}$; then $\Omega$ satisfies the condition (a) of Lemma 1 . When $u \in \partial \Omega \cap \operatorname{ker} L=\partial \Omega \cap R^{4}, u$ is a constant vector in $R^{4}$ with $\|u\|=H$; then we have

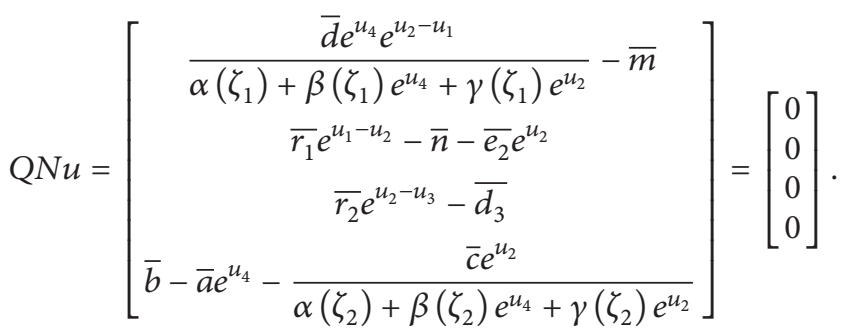

This proves that condition (b) of Lemma 1 is satisfied.

We define the homotopy $J: \operatorname{Dom} L \times[0,1] \rightarrow X$, and a direct calculation shows that

$$
\begin{aligned}
\operatorname{deg}\left(J Q N u, \Omega \cap \operatorname{Ker} L,(0,0,0,0)^{T}\right) \\
=\operatorname{sgn}\left(\frac{\bar{a} \bar{d} \bar{r}_{1} r_{2} e^{2 u_{4}+u_{2}-u_{3}}}{\left(\alpha\left(\zeta_{1}\right)+\beta\left(\zeta_{1}\right) e^{u_{4}}+\gamma\left(\zeta_{1}\right) e^{u_{2}}\right)^{2}}\right)=1 \neq 0 .
\end{aligned}
$$

Therefore $\Omega$ satisfies all the conditions of Lemma 1. Thus, by Lemma 1, we conclude that $L u=N u$ has at least one solution in Dom $L \cap \bar{\Omega}$; that is, the system (9) has at least one $\omega$-periodic solution in $\Omega$. Then, there exists at least one $\omega$-periodic solution for the system (4). The proof is now completed.

\section{Discussion}

In this paper, we have considered a predator-prey system with three-stage-structure for predator, time delay due to predator gestation and prey densities, and BeddingtonDeAngelis functional response. We have derived criteria for the existence of a positive periodic solution. The method used to obtain the main result involves application of Mawhin's continuous theorem of coincidence degree theory and integral inequalities.

Chen et al. [8] considered a delayed predator-prey system with Holling II type response and structure for predator. If the predator $x_{2}$ is absent and the coefficients $\alpha(t) \equiv 1, \beta(t) \equiv$ $m$ (constant), and $\gamma(t) \equiv 0$, the corresponding subsystems of the system (4) are system (3); that is, the system of [8] belongs to the case of the system (4). The conditions for the existence of a positive periodic solution of the system (4) remain the same if delay is absent; thus the delay is "harmless" for the existence of a positive periodic solution of the system (4).

In a word, despite considering the three-stage-structure, people can more protect the beneficial insect from dying out and under the preconditions; the actualization of the periodic changes is more convenient and realistic. The results accord with the change in the natural environments, so the consideration of stage-structure is necessary and important.

\section{Conflict of Interests}

The authors declare that there is no conflict of interests regarding the publication of this paper.

\section{Acknowledgments}

This work is supported by the Project of the Shanxi Provincial Education Department (nos. J2011101, 2009370, and J2012111) and Lvliang University Foundation Project (nos. ZRXN201205 and ZRQN201204).

\section{References}

[1] Y. Kuang, Delay Differential Equations with Applications in Population Dynamics, Academic Press, Boston, Mass, USA, 1993.

[2] S. Gakkhar, K. Negi, and S. K. Sahani, "Effects of seasonal growth on ratio dependent delayed prey predator system," Communications in Nonlinear Science and Numerical Simulation, vol. 14, no. 3, pp. 850-862, 2009.

[3] H. K. Baek, "Qualitative analysis of Beddington-DeAngelis type impulsive predator-prey models," Nonlinear Analysis: Real World Applications, vol. 11, no. 3, pp. 1312-1322, 2010.

[4] W. G. Aiello and H. I. Freedman, "A time-delay model of singlespecies growth with stage structure," Mathematical Biosciences, vol. 101, no. 2, pp. 139-153, 1990.

[5] M. Bandyopadhyay and S. Banerjee, "A stage-structured preypredator model with discrete time delay," Applied Mathematics and Computation, vol. 182, no. 2, pp. 1385-1398, 2006.

[6] Z. J. Gui and W. G. Ge, "The effect of harvesting on a predatorprey system with stage structure," Ecological Modelling, vol. 187, no. 2-3, pp. 329-340, 2005.

[7] F. Chen and M. You, "Permanence, extinction and periodic solution of the predator-prey system with BeddingtonDeAngelis functional response and stage structure for prey," Nonlinear Analysis: Real World Applications, vol. 9, no. 2, pp. 207-221, 2008. 
[8] F. D. Chen, X. Y. Chen, and H. Y. Zhang, "Positive periodic solution of a delayed predator-prey system with Holling type II functional response and stage structure for predator," Acta Mathematica Scientia, vol. 26, no. 1, pp. 093-103, 2006.

[9] Q. Q. Gao and Z. J. Luo, "Periodic solution for nonautonomous stage-structured competitive system with time delays and cannibalism," Journal of Biomathematics, vol. 26, no. 1, pp. 1-8, 2011.

[10] Z. Q. Liang and L. S. Chen, "Existence of positive periodic solution of a nonautonomous single species model with three stage structure," Journal of Central China Normal University, vol. 39, no. 2, pp. 149-153, 2005.

[11] S. J. Gao and L. S. Chen, "Permanence and global stability for single species model with three life stage structure and tone delay," Acta Mathematica Scientia, vol. 26, no. 4, pp. 527-533, 2006.

[12] Y. Dai, T. J. Xing, and Z. X. Luo, "Positive periodic solution of the models with three life stage structures, cannibalism and time delay," Mathematics in Practice and Theory, vol. 4, no. 8, pp. 8591, 2011.

[13] R. Arditi and L. R. Ginzburg, "Coupling in predator-prey dynamics: ratio-dependence," Journal of Theoretical Biology, vol. 139, no. 3, pp. 311-326, 1989.

[14] M. Fan and Y. Kuang, "Dynamics of a nonautonomous predator-prey system with the Beddington-DeAngelis functional response," Journal of Mathematical Analysis and Applications, vol. 295, no. 1, pp. 15-39, 2004.

[15] R. E. Gaines and J. L. Mawhin, Concidence Degree and Nonlinear Differential Equations, Springer, Berlin, Germany, 1997. 


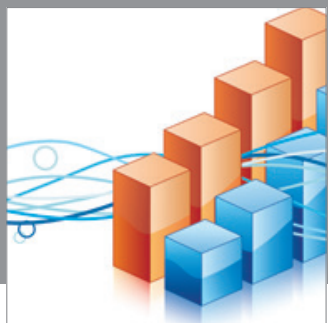

Advances in

Operations Research

mansans

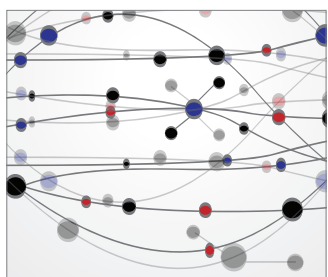

The Scientific World Journal
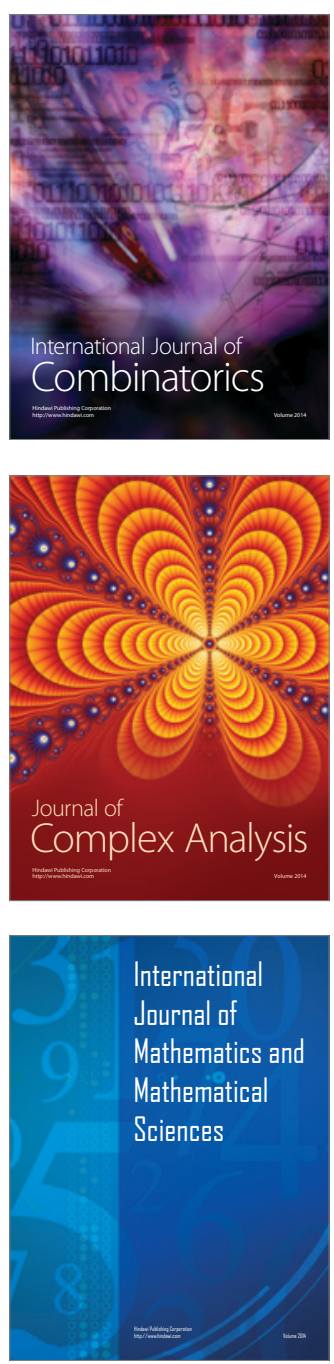
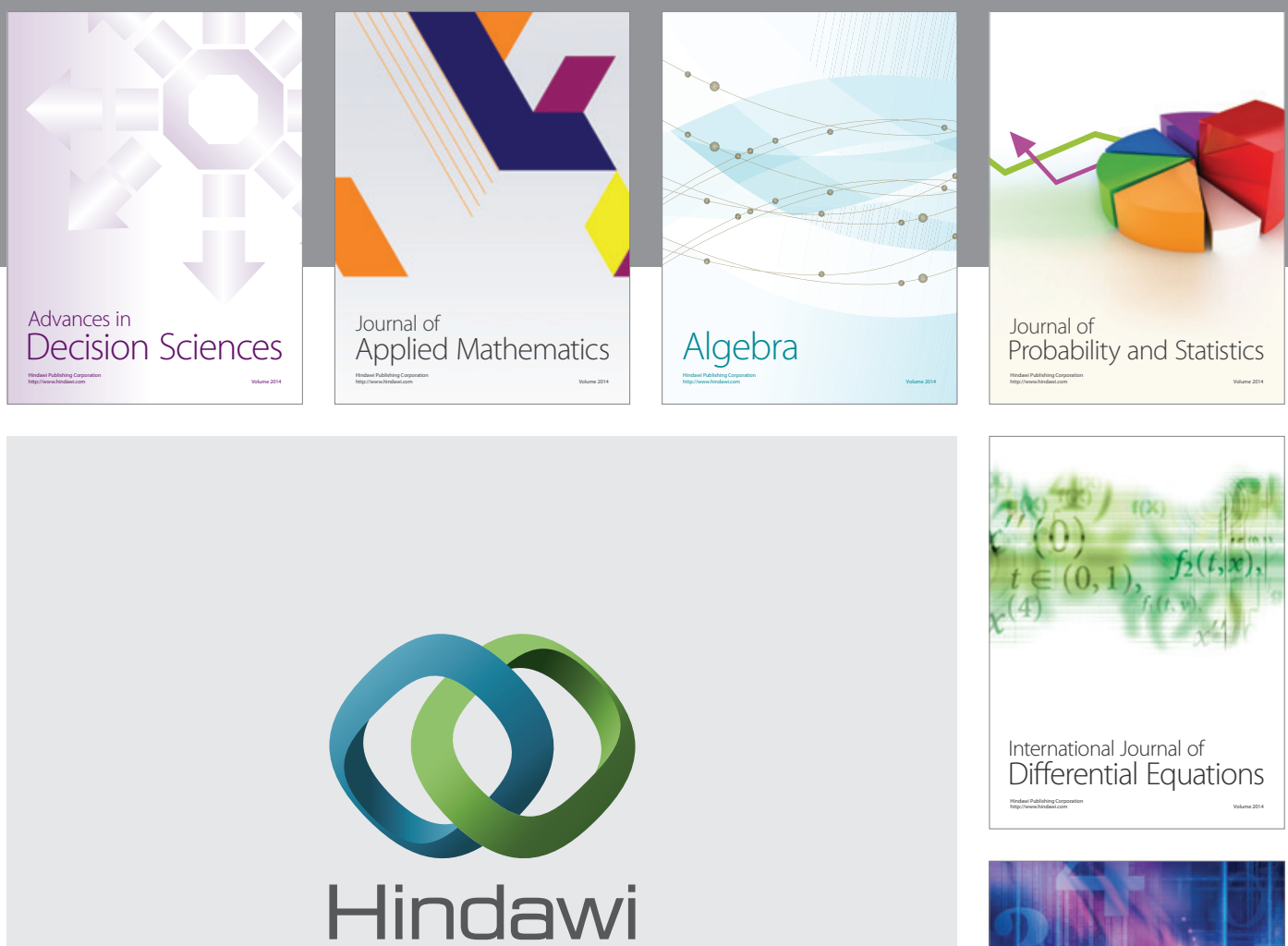

Submit your manuscripts at http://www.hindawi.com
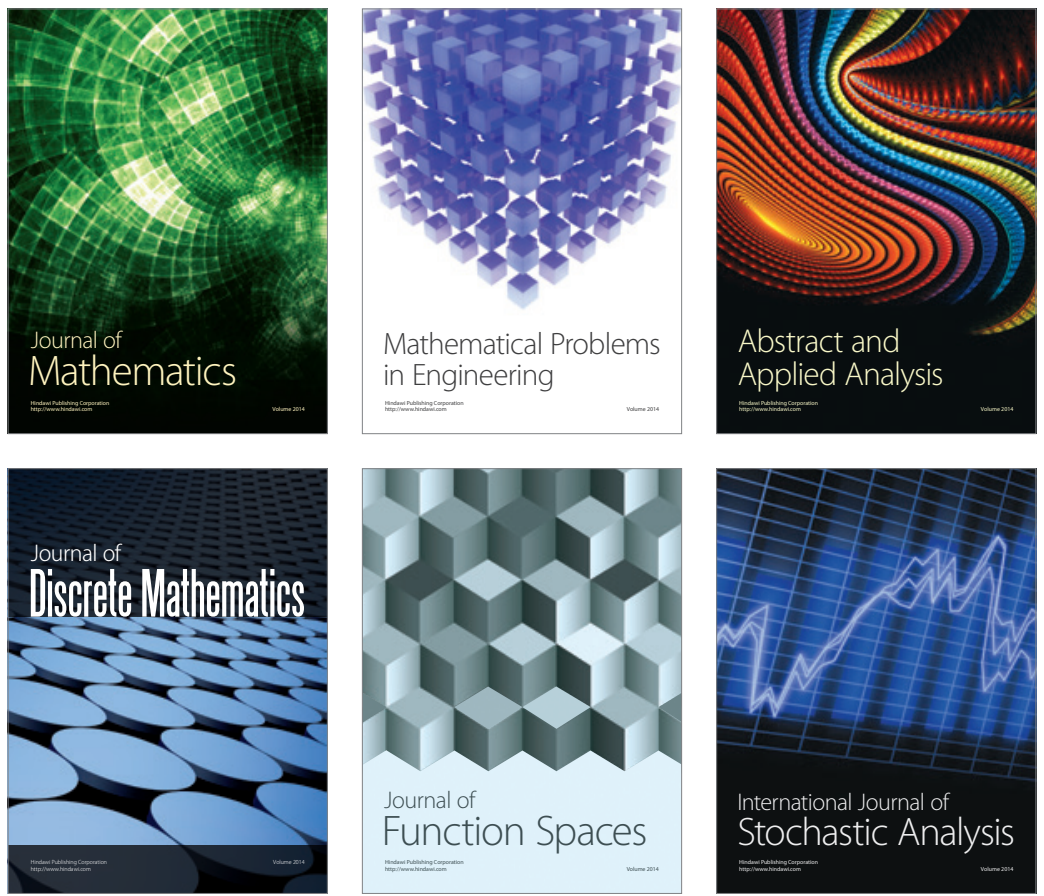

Journal of

Function Spaces

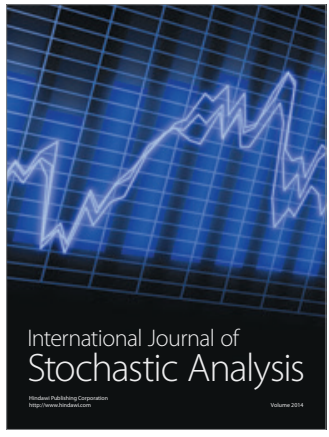

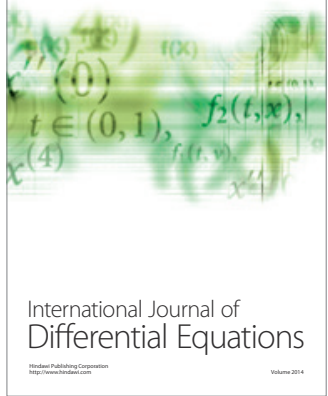
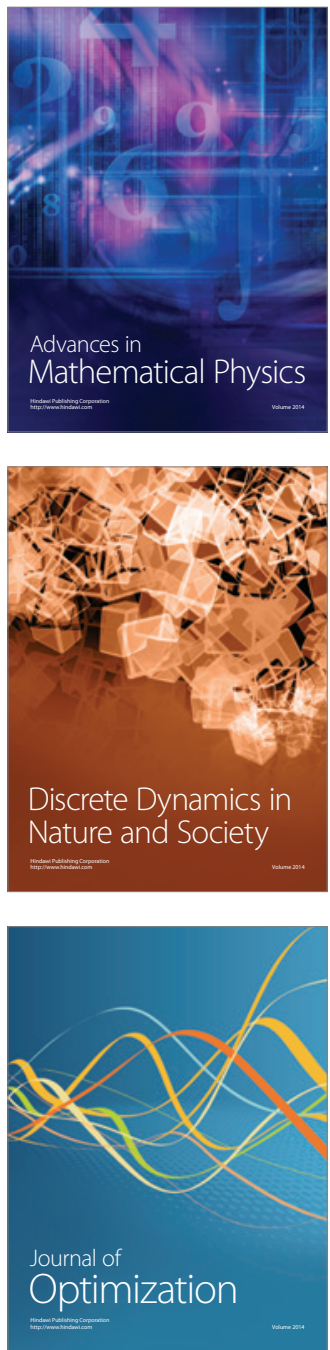